\title{
Product Innovation and Network Survival in the U.S. ATM and Debit Card Industry
}

\author{
Fumiko Hayashi and Zhu Wang*
}

January, 2011

\begin{abstract}
This paper provides a model to explain the shakeout of the U.S. ATM and debit card industry, which emphasizes the role that a major product innovation introducing the debit function in the mid 1980s - played in driving the network consolidation. Consistent with the theory, our empirical findings show that large networks had a better chance of adopting the debit innovation and surviving the shakeout. However, in contrast to previous studies, we find little advantage of being an early entrant in this network industry. Rather, ownership and organizational structure had an important influence on network size and survival.
\end{abstract}

JEL classification: L10; O30; G2

Keywords: Product Innovation; Network Survival; Shakeout

\footnotetext{
*Economic Research Department, Federal Reserve Bank of Kansas City, 1 Memorial Drive, Kansas City, MO 64198. Emails: fumiko.hayashi@kc.frb.org; zhu.wang@kc.frb.org. We thank Ernie Berndt, Tim Simcoe and participants at the 2010 NBER Summer Institute Productivity Potpourri Meeting for helpful comments, and Elizabeth Antonious for valuable research assistance. The views expressed herein are solely those of the authors and do not necessarily reflect the views of the Federal Reserve Bank of Kansas City or the Federal Reserve System.
} 


\section{Introduction}

As an industry evolves from birth to maturity, we typically observe price falls, output rises, and firm numbers initially rise and later fall (Gort and Klepper, 1982; Klepper and Graddy, 1990). Eventually, only a small number of firms survive and the market becomes concentrated. The non-monotonic time path of firm numbers, termed as "shakeout," is the focus of many recent studies of industrial economics. Two important questions have been debated in the literature: First, what drives the industry shakeout? Second, which firms are more likely to survive the shakeout and why?

Regarding the first question, some studies suggest that technological changes play an important role. It has been shown that the industry shakeout can be triggered by "emergence of dominant design" (Utterback and Suárez, 1993), "race of innovation" (Wang, 2007; Jovanovic and MacDonald, 1994), and "scale economies in R\&D" (Klepper and Simons, 2000; Klepper, 1996). In addition, Wang (2008) shows that the evolving consumer demand over industry life cycle may also contribute to the shakeout.

The second question has also attracted much attention. Many studies consider technological advantages and scale economies, often related to firm age (cohort), as the critical factors that determine firm performance and survival. Analyzing the emergence of large-scale enterprise in the U.S., Britain and Germany, Chandler (1990) found that early industry entrants tend to perform better and survive longer due to their "first-mover advantages." The view is strongly supported by recent empirical studies on shakeouts of several U.S. manufacturing industries (Klepper and Simons, 2005).

This paper explores these two questions in the context of the U.S. ATM and debit card industry. Unlike most manufacturing industries studied in the literature, the ATM and debit card industry is a financial service industry featuring strong network effects. ${ }^{1}$

\footnotetext{
${ }^{1}$ There has been a growing literature on the ATM and debit card industry, but our paper is the first one to analyze the shakeout in this industry. Other papers studied ATM adoption (Saloner and Shepard 1995; Hannan and McDowell, 1984), ATM surcharges (Hannan, 2007; Massoud and Bernhard 2002), ATM compatibility (Knittel and Stango, 2008; Hannan and Borzekowski, 2007), banking competition (Ishii, 2005; Matutes and Padilla, 1994) and consumer welfare (Knittel and Stango, 2008; Gowrisankaran and Krainer, 2006). Some other studies looked at the two-sided market effects on debit transactions (Hermalin and Katz, 2006).
} 
In the early 1970s, the industry started with a few shared ATM (Automated Teller Machine) networks, in which ATMs were shared among multiple financial institutions. The number of shared networks grew rapidly to more than 120 in the mid 1980s, but declined sharply afterwards. This raises interesting research questions: What drove the industry shakeout in spite of the rising ATM transaction volume? ${ }^{2}$ Which ATM networks had fared better than others through the consolidation?

While the existing theories shed light on certain aspects of these questions, this paper focuses on a new perspective - the role of network-enhancing product innovation. Particularly, we construct a theoretical model of industry shakeout emphasizing the role that a major product innovation - introducing the debit function in the mid 1980s played in driving the network consolidation. The debit innovation greatly enhances the function of ATM cards, allowing customers to use them not only at ATMs but also at retail locations to pay for goods and services. This extends the industry from a one-sided market of ATM services into a two-sided market serving both consumers and merchants at the point of sale (POS). As a result, the enhanced network effects spurred a race of adopting the debit function, in which large ATM networks had better advantages given their cardholder base and infrastructures in place. Eventually, the winners of the race survived and expanded, and the losers had to exit. The theory is supported by our empirical findings, which show that large networks had a better chance of adopting the debit innovation and surviving the shakeout. Moreover, in contrast to previous studies, we do not find that early entrants in this industry enjoyed strong first-mover advantages, but rather they suffered some disadvantages in organizational structure that negatively affected their size and survival.

The paper is organized as follows. Section 2 provides the background of the U.S. ATM and debit card industry. Section 3 presents our theoretical model that characterizes the impact of a major product innovation - introducing the debit function - on industry dynamics. Section 4 takes our theory to the empirical study using a novel dataset on network entry, exit, size, location, ownership and product choices. Section 5 concludes.

\footnotetext{
${ }^{2}$ According to the EFT Data Book, the U.S. ATM transaction volume continued strong growth between 1985 and 2000, with an average annual growth rate of $8.5 \%$.
} 


\section{Industry Background}

The late 1960s marked the beginning of modern ATM and debit card industry. The first ATMs were basically cash-dispensing machines. ${ }^{3}$ By the early 1970s, ATM technology had advanced to the system we know today. ATMs were developed to take deposits, transfer money between checking and savings accounts, provide cash advances from credit cards, and take payments. ATMs also were connected to computers, allowing real-time access to information about cardholder account balances and activity. By connecting ATMs of multiple financial institutions (banks) to a centralized system, shared networks began to emerge in the early 1970s (Felgran, 1984).

Shared ATM networks generally take one of two forms of organization. First, a financial institution with a proprietary network can share with franchisees who purchase access to an entire system of terminals and computers. In this case, the proprietary network drives all the ATMs and does all the processing for the franchisees. Second, several financial institutions can share a network through a joint venture. As in the cases of any joint venture, ownership is divided in some way. Whether all or only some network participants share the ownership depends on the arrangements made. In some cases, a third party such as a data processing company may retain an interest in the network. In later years, especially after the mid 1990s, nonbank ownership has become increasingly popular.

A shared network allows cardholders to use any ATMs of participating banks in the network. This not only enhances consumer convenience but also extends the geographic service area of banks. In the early years of the industry, most shared ATM networks were regional in scope. ${ }^{4}$ In return for providing the sharing service, networks charge fees to participating banks, which then pass the charges to their customers. ${ }^{5}$

\footnotetext{
${ }^{3}$ In 1967, England's Barclays Bank installed the first cash dispenser. In 1968, Don Wetzel developed the first ATM in the United States using the modern magnetic stripe access card.

${ }^{4}$ In some cases, some regional networks might establish sharing agreements allowing one network's cardholders to access another network's ATMs under certain conditions and payments, but each network would maintain its separate identity and revenue.

${ }^{5}$ In reality, a bank either charges its customers explicit fees for card transactions (e.g., per-transaction fees or annual fees) or bundles the fees with other banking services.
} 


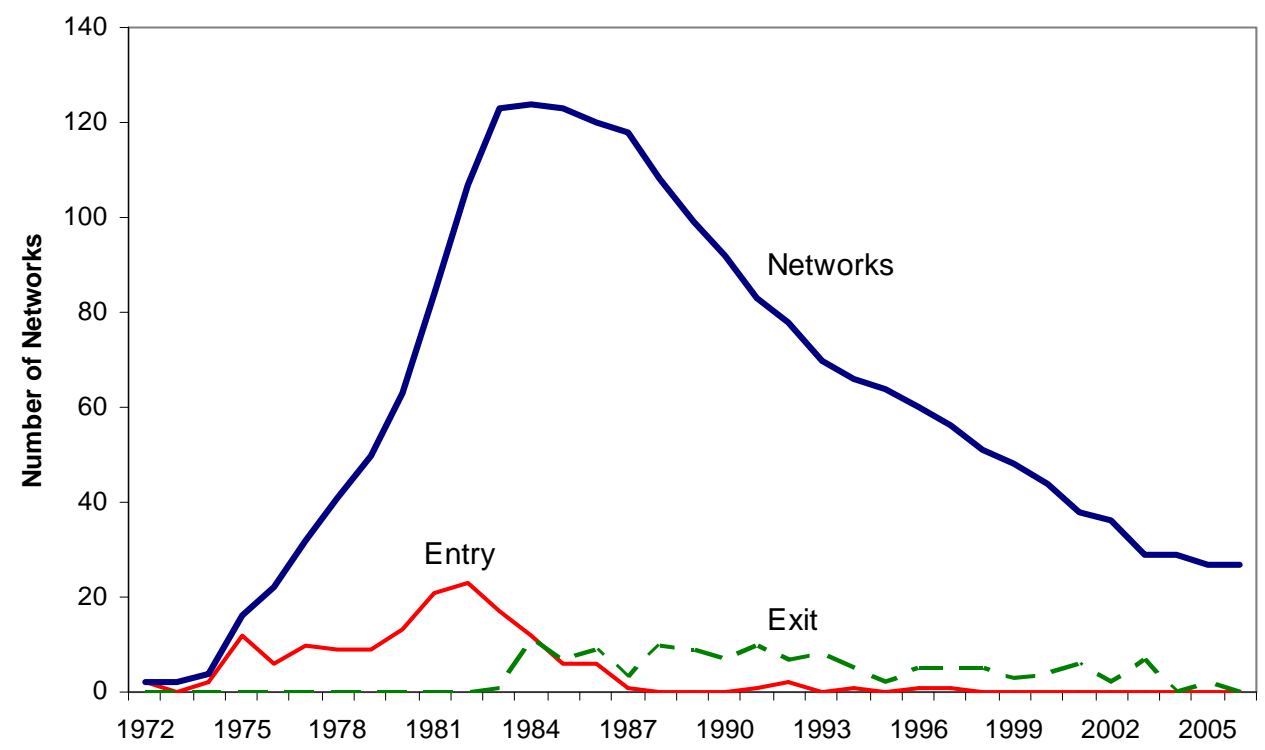

Figure 1: Entry, Exit and Number of Shared Networks

The 1970s saw steady growth of shared ATM networks and the number of networks peaked around 120 in the mid 1980s. However, the industry went through a big shakeout afterwards. Half of the networks had exited by the mid 1990s and less than 30 networks survived to 2006. Figure 1 plots entry, exit and the number of shared networks from 1972 to $2006 .^{6}$

Several major events could have contributed to the shakeout. First, the U.S. Supreme Court ruled in 1985 that ATMs did not represent bank branches so they were not subject to the interstate branching restrictions. By removing a potential barrier to forming networks across state lines, the U.S. Supreme Court decision may have facilitated the industry consolidation to some extent. ${ }^{7}$

Second, the POS debit function was introduced in the mid 1980s, which allows consumers to use ATM/debit cards to pay for goods and services at retail locations. Besides replacing the costly paper-based payments, the debit innovation extended the industry

\footnotetext{
${ }^{6}$ Data Source: EFT Data Book's various issues.

${ }^{7}$ However, the interstate branching restrictions were certainly not the only factor limiting network size. In fact, multiple networks within each single state were very popular at the time. For example, Illinois and Kansas each had 11 networks, Ohio had 10 networks and Florida had 9 networks in 1984 (Felgran, 1984).
} 
from a one-sided market of ATM services into a two-sided market serving both consumers and merchants at the point of sale. The enhanced network effects and scale economies made it increasingly economic to operate larger networks (Felgran, 1985). In the following decade, the industry experienced substantial development in networks' adoption of the debit function. By 1987, 34 percent networks had adopted debit capability and the ratio rose to 54 percent in 1995 . As a result, the debit innovation had important impact on the industry evolution.

Third, several other changes took place after the mid 1990s which may have contributed to the industry consolidation at the later stage. Those changes include interstate banking deregulation and rising nonbank ownership of networks. ${ }^{8}$

While multiple factors are associated with the shakeout, our analysis focuses on the impact of the debit innovation. In the next section, we construct a theoretical model that characterizes the process how the debit innovation triggers an adoption race and drives the shakeout. We then take the theory to data in Section 4. Our empirical study allows for the possibility that multiple factors may have contributed to the shakeout, and provides evidence that the debit innovation played an important role.

\section{Theory}

We construct an industry life cycle model in the spirit of Jovanovic and MacDonald (1994), in which forward-looking networks make optimal decisions on entry, exit and product choice in a competitive market. Given the context of the ATM and debit card industry, we build two important features in the model. First, we consider networks to be heterogenous in size and they provide different quality of products and services. ${ }^{9}$ Second, we model the debit function as a network-enhancing product innovation (instead of a cost-saving technological innovation) that drives the industry evolution.

\footnotetext{
${ }^{8}$ For example, the Riegle-Neal Act was passed in September 1994, allowing banks and bank-holding companies to freely establish branches across state lines. Nonbank ownership of networks has also increased. Among the top 20 regional networks, the number of nonbank-owned networks was two in 1990 and six in 2000 (See Hayashi, Sullivan and Weiner 2003).

${ }^{9}$ The quality of card services refers to the convenience benefit of card usage to cardholders, which depends on the card network size and card functions.
} 


\subsection{Model Setup}

The model is cast in discrete time and infinite horizon. The environment is a competitive market for ATM and debit card services. Two generations of cards appear on the market subsequently. The first one is an ATM-only card, which allows card users to withdraw cash from ATMs. The second generation is the ATM/debit card, which allows card users to withdraw cash from ATMs as well as pay at the point of sale (POS).

On the supply side, the ATM and debit card services are provided by shared networks. During the first generation of cards, ATM-only networks exist. We assume there are two sizes of ATM-only networks, small $s$ and large $l$. After the second generation of cards is introduced, ATM/debit networks become available. We assume there is one size of ATM/debit networks, denoted as $d$. Each network charges a fee $P^{i}$ per card according to the network type $i=\{s, l, d\}$, and incurs an initial fixed cost as well as variable costs to operate. ${ }^{10}$

On the demand side, consumers use card services provided by a shared network through their banks. There is a continuum of banks of mass one in the market. For simplicity, we assume each bank serves the same number of customers, which is normalized to be one. ${ }^{11}$ To provide its customers ATM or ATM/debit services, banks need to participate in a shared network and pay a fee $P^{i}$ per card to the network according to the network type $i=\{s, l, d\}$.

When banks decide which network to join, they consider the quality of the card services provided by different networks. Naturally, an ATM/debit card is more beneficial to the card users than an ATM-only card because of the additional debit function, and an ATM-only card issued by a large network is better than an ATM-only card issued by a small network because the former can be used at more ATM locations. Let $\alpha^{i}$ denote the quality of card services, and we hence assume $\alpha^{d}>\alpha^{l}>\alpha^{s}$. For a bank, offering ATM or ATM/debit services raises its customers' willingness to pay for banking services and increases its total revenue by $\alpha^{i} \theta$. Here $\theta$ is a bank-specific factor, which refers to

\footnotetext{
${ }^{10}$ Note that assuming networks charge per transaction fees instead of per card fees would not affect our analysis since the number of card transactions is closely related with the number of cards.

${ }^{11}$ Note that bank size does not play a role in our analysis so this is an innocuous assumption.
} 
its customers' general preference for card services. We assume $\theta$ is distributed across banks according to the cdf function $G(\theta)$ on $[0,+\infty)$, where $G(0)=0$ and $G(+\infty)=1$. Therefore, for each bank, the net revenue per card is expressed as

$$
R\left(\theta ; \alpha^{i}, P^{i}\right)=\alpha^{i} \theta-P^{i}, \quad i=\{s, l, d\}
$$

\subsection{Before the Debit Innovation}

The market starts at time 0 when the shared ATM service becomes available. Potential network entrants, denoted by $\phi$, are of an infinite measure. Each period, a potential entrant may choose to enter the market or take an outside option with a payoff $\pi^{\phi}$. An entrant pays an initial fixed cost to set up a shared ATM network. There are two options: One is to pay a high fixed cost $K^{l}$ to set up a large network; the other is to pay a low fixed cost $K^{s}$ to set up a small network. After entering the industry, a network can choose to change its size. Upgrading a small network to a large network requires an additional cost (e.g., $K^{l}-K^{s}$ ). Downsizing or exiting does not incur additional costs, but the initial sunk costs can not be recovered.

For each network type $i=\{s, l\}$, the return at time $t$ is a profit flow of $\pi_{t}^{i}$, which depends on price $P_{t}^{i}$ and cost $C\left(q_{t}^{i}\right)$; i.e., $\pi_{t}^{i}=\max _{q_{t}^{i}}\left\{P_{t}^{i} q_{t}^{i}-C\left(q_{t}^{i}\right)\right\}$. Here $C$ refers to a convex cost function, and $q_{t}^{i}$ is the quantity supplied by network $i$ in terms of its number of ATM cards in circulation. ${ }^{12}$ Since the cost function has the standard properties, we have $\partial \pi^{i} / \partial P^{i}>0$ and $\partial q^{i} / \partial P^{i}>0$ for $i=\{s, l\}$.

For simplicity, we assume setting up an ATM network involves no uncertainty, and the probability that future innovations may arrive is too small to affect a network's decision. Hence, at each time $t \geq 0$, we derive the following value functions:

$$
U_{t}^{\phi}=\pi^{\phi}+\max \left\{\beta U_{t+1}^{\phi}, \beta U_{t+1}^{s}-K^{s}, \beta U_{t+1}^{l}-K^{l}\right\}
$$

\footnotetext{
${ }^{12}$ The convex cost reflects the fact that networks have to bear various operational, regulatory and coordinating constraints, which give rise to numerous regional networks.
} 


$$
\begin{gathered}
U_{t}^{s}=\max \left\{\pi^{\phi}+\beta U_{t+1}^{\phi}, \pi_{t}^{s}+\max \left[\beta U_{t+1}^{s}, \beta U_{t+1}^{l}-\left(K^{l}-K^{s}\right)\right]\right\} \\
U_{t}^{l}=\max \left\{\pi^{\phi}+\beta U_{t+1}^{\phi}, \pi_{t}^{s}+\beta U_{t+1}^{s}, \pi_{t}^{l}+\beta U_{t+1}^{l}\right\}
\end{gathered}
$$

where $U_{t}^{\phi}, U_{t}^{s}, U_{t}^{l}$ are the value of a potential entrant $\phi$, a small network $s$ and a large network $l$ at time $t$ respectively, and $\beta$ is the discount factor.

Due to free entry, there exist prices $P^{s^{*}}$ and $P^{l^{*}}$ at which potential network entrants are indifferent between the three options $\phi, s$ and $l$ at time 0 , so that $\beta U_{1}^{\phi}=\beta U_{1}^{s}-K^{s}=$ $\beta U_{1}^{l}-K^{l}$. Therefore, we have

$$
\frac{\beta \pi^{\phi}}{1-\beta}=\frac{\beta \pi^{s}\left(P^{s^{*}}\right)}{1-\beta}-K^{s}=\frac{\beta \pi^{l}\left(P^{l^{*}}\right)}{1-\beta}-K^{l}
$$

Because $K^{l}>K^{s}$, Eq. (1) suggests that $\pi^{l}\left(P^{l^{*}}\right)>\pi^{s}\left(P^{s^{*}}\right)>\pi^{\phi}$. According to the profit function properties, this implies that $P^{l^{*}}>P^{s^{*}}$ and $q^{l}\left(P^{l^{*}}\right)>q^{s}\left(P^{s^{*}}\right)$. Therefore, a large ATM network charges a higher price, earns a higher profit and has more cards in circulation than a small ATM network.

On the demand side, banks choose which network to participate in. ${ }^{13}$ Particularly, banks with a high $\theta\left(\theta>\frac{P^{l^{*}}-P^{s^{*}}}{\alpha^{l}-\alpha^{s}}\right)$ prefer participating in a large network because

$$
\alpha^{l} \theta-P^{l^{*}}>\alpha^{s} \theta-P^{s^{*}} \Longrightarrow \theta>\frac{P^{l^{*}}-P^{s^{*}}}{\alpha^{l}-\alpha^{s}}
$$

Accordingly, the demand for large networks' ATM cards is $D^{l}=1-G\left(\frac{P^{l^{*}}-P^{s^{*}}}{\alpha^{l}-\alpha^{s}}\right)$. Meanwhile, banks with a moderate $\theta\left(\frac{P^{l^{*}}-P^{*}}{\alpha^{l}-\alpha^{s}} \geq \theta \geq \frac{P^{s^{*}}}{\alpha^{s}}\right)$ prefer a small network because

$$
\alpha^{s} \theta-P^{s^{*}} \geq \max \left\{0, \alpha^{l} \theta-P^{l^{*}}\right\} \Longrightarrow \frac{P^{l^{*}}-P^{s^{*}}}{\alpha^{l}-\alpha^{s}} \geq \theta \geq \frac{P^{s^{*}}}{\alpha^{s}} .
$$

Accordingly, the demand for small networks' ATM cards is $D^{s}=G\left(\frac{P^{l^{*}}-P^{s^{*}}}{\alpha^{l}-\alpha^{s}}\right)-G\left(\frac{P^{s^{*}}}{\alpha^{s}}\right)$. Finally, banks with a low $\theta\left(\theta<\frac{P^{s^{*}}}{\alpha^{s}}\right)$ choose not to join any network and they do not provide card services to their customers.

\footnotetext{
${ }^{13}$ Without loss of generality, we assume both small and large networks' cards are in demand at the equilibrium.
} 
The market demand equals supply at the equilibrium. Hence,

$$
\begin{gathered}
D^{l}=1-G\left(\frac{P^{l^{*}}-P^{s^{*}}}{\alpha^{l}-\alpha^{s}}\right)=N^{l} q^{l}\left(P^{l^{*}}\right), \\
D^{s}=G\left(\frac{P^{l^{*}}-P^{s^{*}}}{\alpha^{l}-\alpha^{s}}\right)-G\left(\frac{P^{s^{*}}}{\alpha^{s}}\right)=N^{s} q^{s}\left(P^{s^{*}}\right),
\end{gathered}
$$

where $N^{l}$ and $N^{s}$ are the number of large and small ATM networks respectively.

Note that, at equilibrium, no network has incentive to change its size, and no additional entrant has incentive to enter. For a large network $l$ or a small network $s$, because the initial investment is sunk and $\pi^{l}\left(P^{l^{*}}\right)>\pi^{s}\left(P^{s^{*}}\right)>\pi^{\phi}$, the network would not want to downsize or exit. For a small network $s$ or a potential entrant $\phi$, increasing output would drive down the industry price and does not justify the investment, so the small network or the potential entrant has no incentive to expand or enter.

Equations (1), (2) and (3) describe a simple industry equilibrium path: At time 0, potential entrants make their entry and size decisions. Then, from time 1 and afterwards, there are $N^{l}$ large networks each serving $q^{l}\left(P^{l^{*}}\right)$ cards and $N^{s}$ small networks each serving $q^{s}\left(P^{s^{*}}\right)$ cards. Meanwhile, there are $1-G\left(\frac{P^{l^{*}}-P^{s^{*}}}{\alpha^{l}-\alpha^{s}}\right)$ banks that demand large networks'

cards at the price $P^{l^{*}}$, and $G\left(\frac{P^{l^{*}}-P^{s^{*}}}{\alpha^{l}-\alpha^{s}}\right)-G\left(\frac{P^{s^{*}}}{\alpha^{s}}\right)$ banks that demand small networks' cards at the price $P^{s^{*}}$. The industry supply for each type of cards meets the demand. There is no further industry dynamics.

\subsection{After the Debit Innovation}

At time $T$, the debit innovation arrives as an unexpected shock. As a result, networks have chance to offer a superior product, the ATM/debit card. To set up an ATM/debit network $d$, a new entrant $\phi$, a small ATM network $s$ or a large ATM network $l$ needs to invest a fixed cost $I^{\phi}, I^{s}$ or $I^{l}$, respectively. Naturally, we assume $I^{\phi}>I^{s}>I^{l}$. We also assume there is uncertainty associated with setting up an ATM/debit network. Namely, for a type $i$ network, $i=\{\phi, s, l\}$, the attempt may succeed with probability $\lambda^{i}$ or the network may fail and remain its original type. Once succeed, the profit flow of an 
$\mathrm{ATM} /$ debit network $\pi_{t}^{d}$ depends on the price $P_{t}^{d}$ and $\operatorname{cost} C\left(q_{t}^{d}\right)$, i.e., $\pi_{t}^{d}=\max _{q_{t}^{d}}\left\{P_{t}^{d} q_{t}^{d}-\right.$ $\left.C\left(q_{t}^{d}\right)\right\}$.

The probability of successfully setting up an ATM/debit network is assumed to vary by network type. Particularly, a large ATM network is more likely to succeed than a small ATM network, and a small ATM network is more likely to succeed than a new entrant, i.e., $\lambda^{l}>\lambda^{s}>\lambda^{\phi}$. This is due to two important reasons. First, for a debit system to function, a network needs to bring both merchants and consumers on board. A large ATM network, with a bigger cardholder base, is more attractive for merchants and consumers to accept or use its debit cards. Second, a large ATM network, with better infrastructures in place, needs to invest less to adopt the debit function, i.e., $I^{l}<I^{s}<I^{\phi}$. This may also help raise its probability of success.

Because of the new profit opportunity, networks need to reconsider their entry, exit and product choice. At each time $t \geq T$, the following value functions are for a new entrant $\phi$, a small ATM-only network $s$, a large ATM-only network $l$ and an ATM/debit network $d$ respectively.

$$
\begin{gathered}
V_{t}^{\phi}=\pi^{\phi}+\max \left\{\beta V_{t+1}^{\phi}, \beta V_{t+1}^{s}-K^{s}, \beta V_{t+1}^{l}-K^{l},\right. \\
\left.\beta\left[\lambda^{\phi} V_{t+1}^{d}+\left(1-\lambda^{\phi}\right) V_{t+1}^{\phi}\right]-I^{\phi}\right\}, \\
V_{t}^{s}=\max \left\{\pi^{\phi}+\beta V_{t+1}^{\phi}, \pi_{t}^{s}+\max \left[\beta V_{t+1}^{s}, \beta V_{t+1}^{l}-\left(K^{l}-K^{s}\right),\right.\right. \\
\left.\left.\beta\left(\lambda^{s} V_{t+1}^{d}+\left(1-\lambda^{s}\right) V_{t+1}^{s}\right)-I^{s}\right]\right\}, \\
V_{t}^{l}=\max \left\{\pi^{\phi}+\beta V_{t+1}^{\phi}, \pi_{t}^{s}+\beta V_{t+1}^{s}, \pi_{t}^{l}+\max \left[\beta V_{t+1}^{l},\right.\right. \\
\left.\left.\beta\left(\lambda^{l} V_{t+1}^{d}+\left(1-\lambda^{l}\right) V_{t+1}^{l}\right)-I^{l}\right]\right\}, \\
V_{t}^{d}=\max \left\{\pi^{\phi}+\beta V_{t+1}^{\phi}, \pi_{t}^{s}+\beta V_{t+1}^{s}, \pi_{t}^{l}+\beta V_{t+1}^{l}, \pi_{t}^{d}+\beta V_{t+1}^{d}\right\} .
\end{gathered}
$$


Equations (4) to (7) imply the following:

- A potential entrant $\phi$ has four options: (1) staying outside the industry; (2) paying a fixed cost $K^{s}$ to enter as a small ATM-only network; (3) paying a fixed cost $K^{l}$ to enter as a large ATM-only network; (4) paying a fixed cost $I^{\phi}$ to try setting up an ATM/debit network with the probability of success $\lambda^{\phi}$.

- A small ATM-only network $s$ has four options: (1) exiting the industry; (2) staying as it is; (3) paying a fixed cost $\left(K^{l}-K^{s}\right)$ to upgrade to a large ATM-only network; (4) paying a fixed cost $I^{s}$ to try upgrading to an ATM/debit network with the probability of success $\lambda^{s}$.

- A large ATM-only network $l$ has four options: (1) exiting the industry; (2) downgrading to a small ATM-only network; (3) staying as it is; (4) paying a fixed cost $I^{l}$ to try upgrading to an ATM/debit network with the probability of success $\lambda^{l}$.

- An ATM/debit network $d$ does not need further investment, and can choose whatever option $\phi, s, l$ or $d$ to pursue the highest profit.

\subsection{Industrial Evolution: Characterization}

The debit innovation creates a superior product, the ATM/debit card. Because an ATM/debit card offers enhanced services than ATM-only cards (i.e., $\alpha^{d}>\alpha^{l}>\alpha^{s}$ ), it also charges a higher price (i.e., $P_{t}^{d}>P_{t}^{l}>P_{t}^{s}$ ) at the equilibrium. ${ }^{14}$ The profit function properties suggest that $\pi^{d}\left(P_{t}^{d}\right)>\pi^{l}\left(P_{t}^{l}\right)>\pi^{s}\left(P_{t}^{s}\right)$ and $q^{d}\left(P_{t}^{d}\right)>q^{l}\left(P_{t}^{l}\right)>q^{s}\left(P_{t}^{s}\right)$. Therefore, an ATM/debit network charges a higher price, earns a higher profit and has more cards in circulation than an ATM-only network.

We may denote the mass of the three types of networks at time $t$ to be $n_{t} \equiv\left(n_{t}^{s}, n_{t}^{l}, n_{t}^{d}\right)$ and characterize the industry dynamics. Note that depending on model parameter values, a number of equilibrium paths may exist. To keep our discussion focused, we discuss one equilibrium path that most resembles the empirical pattern.

\footnotetext{
${ }^{14}$ Note that if a low-quality card charges a higher price than a high-quality card, it would have no demand.
} 
At time $T$, as long as the entry cost $I^{\phi}$ can be justified by the potential profits, a number $N^{\phi}$ of new entrants attempt to set up ATM/debit networks. Meanwhile, all existing ATM-only networks attempt to adopt the debit innovation. ${ }^{15}$ Since it takes one period for the adoption to take effect, there is no change in price and output at time $T$.

At time $T+1$, among all the $N^{\phi}$ entry attempts, a fraction $\lambda^{\phi}$ successfully enters as ATM/debit network and $\left(1-\lambda^{\phi}\right)$ fails and exits. Among the $N^{l}\left(N^{s}\right)$ large (small) incumbent networks, a fraction $\lambda^{l}\left(\lambda^{s}\right)$ succeeds in becoming ATM/debit networks. The rest of the networks have to try adopting the innovation again in the next period. As the supply increases, the price of ATM/debit cards $P^{d}$ is expected to fall over time, so no more entry from outside the industry is profitable at time $T+1$ and afterwards.

After time $T+1$, more incumbent ATM networks succeed in adopting the debit innovation, so the total number of cards issued keeps rising and the prices of all the three types of cards $P^{s}, P^{l}$ and $P^{d}$ keep falling. ${ }^{16}$ At time $T^{\prime}$, the price $P^{d}$ falls enough so that small ATM-only networks, due to their relatively low success rate $\lambda^{s}$ and high investment $I^{s}$, no longer find it profitable to invest in the debit innovation. Hence, during the period $T+1 \leq t<T^{\prime}$, the number of each type of networks is

$$
\begin{gathered}
n_{t}^{l}=N^{l}\left(1-\lambda^{l}\right)^{t-T}, \quad n_{t}^{s}=N^{s}\left(1-\lambda^{s}\right)^{t-T}, \\
n_{t}^{d}=N^{l}\left[1-\left(1-\lambda^{l}\right)^{t-T}\right]+N^{s}\left[1-\left(1-\lambda^{s}\right)^{t-T}\right]+N^{\phi} \lambda^{\phi} .
\end{gathered}
$$

However, large ATM-only networks continue to try adding the debit function after time $T^{\prime}$. Hence, the supply of ATM/debit cards continues to increase and drives down the card prices $P^{s}, P^{l}$ and $P^{d}$. Eventually, the price of small networks' ATM cards reaches a critical value $P_{T^{\prime \prime}}^{s}$ at time $T^{\prime \prime}$ so that small ATM-only networks become indifferent between staying and exiting the market. During the period $T^{\prime} \leq t<T^{\prime \prime}$, the number of each type of networks is

\footnotetext{
${ }^{15}$ We assume that after the debit innovation arrives, it is not profitable for any new entrant to enter as an ATM-only network, or any small ATM-only network to upgrade to a large ATM-only network.

${ }^{16}$ Note that the three types of cards are substitutes, so the increasing supply of ATM/debit cards pushes down prices for all three types of cards.
} 


$$
\begin{gathered}
n_{t}^{l}=N^{l}\left(1-\lambda^{l}\right)^{t-T}, \quad n_{t}^{s}=N^{s}\left(1-\lambda^{s}\right)^{T^{\prime}-1-T} \\
n_{t}^{d}=N^{l}\left[1-\left(1-\lambda^{l}\right)^{t-T}\right]+N^{s}\left[1-\left(1-\lambda^{s}\right)^{T^{\prime}-1-T}\right]+N^{\phi} \lambda^{\phi} .
\end{gathered}
$$

During the period $T+1 \leq t<T^{\prime \prime}$, the market demand equals supply for the ATM/debit cards $d$ :

$$
D_{t}^{d}=1-G\left(\frac{P_{t}^{d}-P_{t}^{l}}{\alpha^{d}-\alpha^{l}}\right)=n_{t}^{d} q^{d}\left(P_{t}^{d}\right)
$$

and for the ATM-only cards $l$ and $s$ :

$$
\begin{gathered}
D_{t}^{l}=G\left(\frac{P_{t}^{d}-P_{t}^{l}}{\alpha^{d}-\alpha^{l}}\right)-G\left(\frac{P_{t}^{l}-P_{t}^{s}}{\alpha^{l}-\alpha^{s}}\right)=n_{t}^{l} q^{l}\left(P_{t}^{l}\right), \\
D_{t}^{s}=G\left(\frac{P_{t}^{l}-P_{t}^{s}}{\alpha^{l}-\alpha^{s}}\right)-G\left(\frac{P_{t}^{s}}{\alpha^{s}}\right)=n_{t}^{s} q^{s}\left(P_{t}^{s}\right) .
\end{gathered}
$$

At time $T^{\prime \prime}$, the price of small networks' ATM cards reaches the critical value $P_{T^{\prime \prime}}^{s}$ at which $\pi^{s}\left(P_{T^{\prime \prime}}^{s}\right)=\pi^{\phi}$, so some small ATM-only networks start to exit. As a result,

$$
D_{T^{\prime \prime}}^{d}+D_{T^{\prime \prime}}^{l}+D_{T^{\prime \prime}}^{s}=1-G\left(P_{T^{\prime \prime}}^{s} / \alpha^{s}\right)=n_{T^{\prime \prime}}^{d} q^{d}\left(P_{T^{\prime \prime}}^{d}\right)+n_{T^{\prime \prime}}^{l} q^{l}\left(P_{T^{\prime \prime}}^{l}\right)+n_{T^{\prime \prime}}^{s} q^{s}\left(P_{T^{\prime \prime}}^{s}\right) .
$$

This implies that

$$
n_{T^{\prime \prime}}^{s}=\frac{1-G\left(P_{T^{\prime \prime}}^{s} / \alpha^{s}\right)-n_{T^{\prime \prime}}^{d} q^{d}\left(P_{T^{\prime \prime}}^{d}\right)-n_{T^{\prime \prime}}^{l} q^{l}\left(P_{T^{\prime \prime}}^{l}\right)}{q^{s}\left(P_{T^{\prime \prime}}^{s}\right)} .
$$

Hence, the number of exiting small ATM-only networks $x_{T^{\prime \prime}}^{s}$ at time $T^{\prime \prime}$ is

$$
x_{T^{\prime \prime}}^{s}=N^{s}\left(1-\lambda^{s}\right)^{T^{\prime}-1-T}-n_{T^{\prime \prime}}^{s} .
$$

For $t>T^{\prime \prime}$, as the rest of large ATM networks continue to adopt the debit innovation, additional small ATM-only networks exit to keep the price at $P_{T^{\prime \prime}}^{s}$, and the number of exiting networks $x_{t}^{s}$ is determined by 


$$
x_{t}^{s}=\frac{n_{t}^{d} q^{d}\left(P_{t}^{d}\right)+n_{t}^{l} q^{l}\left(P_{t}^{l}\right)-n_{t-1}^{d} q^{d}\left(P_{t-1}^{d}\right)-n_{t-1}^{l} q^{l}\left(P_{t-1}^{l}\right)}{q^{s}\left(P_{T^{\prime \prime}}^{s}\right)} .
$$

Later on, after all small ATM-only networks exit, card prices $P^{d}$ and $P^{l}$ may fall again. Eventually, depending on model parameter values, large ATM-only networks may exit the industry all together or coexist with ATM/debit networks in the long run.

\section{Empirical Analysis}

Our theory characterizes the process how a major product innovation - introducing the debit function - spurs an adoption race and drives the shakeout in the ATM/debit card industry. To check its empirical relevance, we conduct an empirical study in this section using a novel dataset on network entry, exit, size, location, ownership and product choices. The findings confirm the two main hypotheses of our theory. First, large ATM networks have a better chance of adopting the debit innovation. Second, small ATMonly networks tend to exit before large ATM-only networks, and ATM/debit networks are most likely to survive the shakeout. ${ }^{17}$ Moreover, in contrast to previous studies, we find little advantage of being an early industry entrant. Rather, ownership and organizational structure had an important influence on network size and survival.

\subsection{Data}

The data are drawn from various issues of the EFT Data Book from 1985 to $2006{ }^{18}$ The Book lists the leading regional EFT networks (ATM/debit networks or ATM-only networks in our definition) in the United States, and provides each network's (1) year

\footnotetext{
${ }^{17}$ Note that our theory yields a deterministic path: Given a constant outside option, small ATM networks exit the industry first, then followed by large ATM networks. ATM/debit networks survive to the end. To test the theory with data, we then need to add some randomness. For example, if we assume each industry player has an i.i.d. draw of the outside option, then our theory implies that small ATM networks tend to exit before large ATM networks, and ATM/debit networks are most likely to survive the shakeout.

${ }^{18}$ ATMEDDebit News (formerly, Bank Network News) publishes the EFT Data Book annually (EFT stands for "Electronic Funds Transfer").
} 
organized, (2) ownership, (3) headquarter location, (4) membership, (5) the number of cards in circulation, (6) the number of transactions by type (ATM or POS), and (7) the number of terminals by type (ATM or POS).

Our dataset includes 136 regional EFT networks that existed at some point of time during the 1985-2006 period. ${ }^{19}$ Among them, we first exclude networks whose ownership or membership is solely composed of credit unions and/or saving and loan banks (14 networks). Those networks likely behave differently from networks that provide services to commercial banks. We then exclude eight networks that entered the market after 1985, the shakeout year. It is reasonable to set 1985 as the shakeout year. ${ }^{20}$ As shown in Figure 1, the number of network entrants declined significantly after 1985, and the net number of networks also declined for the first time in 1985. Although our sample does not include all the regional networks that ever existed in 1985, it accounts for about 95 percent of all transactions switched through the EFT networks. ${ }^{21}$

For each network, its cohort is based on its year of entry, its location is based on its headquarter address, its ownership type is based on its owner information, and its size is based on its number of cards in circulation. We denote the networks which entered in the 1970s as the early cohort, and the entrants in the 1980s as the late cohort. The network location is categorized into three groups: East, Middle, and West. East consists of three census regions (New England, Mid-Atlantic, and South-Atlantic); Middle consists of four central census regions (East-North, East-South, West-North, and West-South central); and West consists of two census regions (Mountain and Pacific). We use two criteria to characterize network ownership. One is whether the network is owned by a single owner or multiple owners; and the other is whether the network is owned solely by financial institution(s) or not. A network's size is either large or small. The top one-third of the networks ranked by the number of cards in circulation are counted as large networks

\footnotetext{
${ }^{19}$ We exclude national EFT networks, such as Cirrus and Plus (national ATM networks) and Interlink and Maestro (national debit card networks), from our sample because national networks used to play a different role than regional networks. They offered a "bridge" between regional networks. See Hayashi, Sullivan and Weiner (2003) for details.

${ }^{20}$ Note that using 1986 or 1987 as the shakeout year does not affect the results.

${ }^{21}$ The data on switch transactions is from the EFT Data Book 1986 Edition.
} 
and the rest are small networks. Finally, whether each network had adopted POS debit function or not is based on the information of POS terminals deployed in the network. The summary statistics of the data are reported in Table 1.

\subsection{Debit Adoption}

The first hypothesis we test is that large ATM networks are more likely to adopt the debit innovation than small networks. This hypothesis is first evaluated using Table 1, which compares the sample means between POS debit adopters and non-adopters. Each network's size, ownership type, and location are based on its 1985 characteristics. We categorize a network as a POS adopter if it had adopted the POS debit function by the end of 1987. Among 114 networks in our sample, 39 are found to be POS adopters.

The findings support the hypothesis. The average size of POS adopting networks is much larger than non-adopters, and the difference is statistically significant at the 1 percent level. In fact, 56 percent of POS adopting networks are large networks, ranked among the top one-third of all the networks by the number of cards in circulation. In contrast, only 23 percent of non-adopters are large networks. On average, a POS adopting network has three times the number of cards in circulation as a non-adopting network. However, we find no statistically significant difference between POS adopters and non-adopters in terms of their entry cohort, ownership, and location.

As a further step, we conduct logit regressions to examine what factors significantly affect POS debit adoption. The results are reported in Table 2. The dependent variable is POS debit adoption by 1987. Independent variables are based on networks' 1985 characteristics. Specifications 1 and 2 include early cohort, location and ownership dummies as independent variables. However, none of these variables is statistically significant. In specification 3, a dummy variable indicating a large network enters along with all other independent variables. The coefficient of the Large dummy turns out to be positive and is the only one statistically significant. This suggests that the chance of adopting POS debit increases with network size, but other factors, such as early cohort, ownership and location, have no significant effect. 
Table 1. Summary Statistics: Sample Means

\begin{tabular}{lccc}
\hline \hline Variable & $\begin{array}{c}\text { All } \\
\text { networks }\end{array}$ & $\begin{array}{c}\text { POS } \\
\text { adopters }\end{array}$ & $\begin{array}{c}\text { Non- } \\
\text { adopters }\end{array}$ \\
\hline Cohort & & & \\
$\quad$ Entry year & 1980.29 & 1979.97 & 1980.46 \\
$\quad$ Early cohort & 0.281 & 0.359 & 0.240 \\
Size & & & \\
$\quad$ Number of cards*** & 781,498 & $1,390,499$ & 464,817 \\
$\quad$ Large** & 0.333 & 0.564 & 0.213 \\
Ownership & & & \\
$\quad$ Single owner & 0.623 & 0.667 & 0.600 \\
$\quad$ Bank owner(s) & 0.807 & 0.795 & 0.813 \\
Location & & & \\
$\quad$ East & 0.246 & 0.205 & 0.267 \\
$\quad$ West & 0.158 & 0.179 & 0.147 \\
Number of networks & 114 & 39 & 75 \\
\hline
\end{tabular}

Notes: Ownership, location, and size are based on the networks' 1985 characteristics. POS adopters are the networks that had adopted POS debit by 1987. ***: The difference between POS adopters and non-adopters is statistically significant at the 0.01 level.

Table 2. Logit Models: POS Debit Adoption by 1987

\begin{tabular}{lccc}
\hline \hline \multirow{2}{*}{ Variable } & \multicolumn{3}{c}{ Specification } \\
\cline { 2 - 4 } Constant & 1 & 2 & 3 \\
\multirow{2}{*}{ Early cohort } & $-0.798^{* * *}$ & -0.693 & $-1.573^{* *}$ \\
& $(0.303)$ & $(0.576)$ & $(0.688)$ \\
East & 0.542 & 0.561 & 0.384 \\
& $(0.437)$ & $(0.458)$ & $(0.505)$ \\
West & -0.202 & -0.193 & -0.880 \\
& $(0.500)$ & $(0.503)$ & $(0.587)$ \\
Single owner & -0.190 & 0.154 & -0.239 \\
& $(0.551)$ & $(0.555)$ & $(0.627)$ \\
Bank owner(s) & & 0.137 & 0.744 \\
& & $(0.431)$ & $(0.511)$ \\
Large & & -0.242 & -0.244 \\
& & $(0.517)$ & $(0.573)$ \\
Log likelihood & & & $2.074^{* * *}$ \\
\hline
\end{tabular}

Notes: Standard errors are in parentheses. Ownership, location, and size are based on the networks' 1985 characteristics. ***, **: Significant at the .01 and .05 level, respectively. 
In order to provide some intuitive interpretation for our results, we construct the predicted probability of adopting POS debit, according to network size. We construct these probabilities for networks owned by a single bank, located in the Middle region, and entered in 1980 or later (late cohort). The predicted probability that a large network had adopted POS debit by 1987 is 78 percent, while the probability for a small counterpart is only 30 percent.

\subsection{Network Survival}

\subsubsection{Base Regressions}

The second hypothesis we test is that ATM/debit networks are more likely to survive than ATM-only networks, and among ATM-only networks large networks are more likely to survive than small ones. Note that defining "exit" is critical for our analysis in this subsection because the ATM and debit card industry experienced a quite large number of mergers and acquisitions.

We observe two types of network exit: One is simply exiting from the market without merger or acquisition; and the other is being acquired by or merged with another network and terminating the network brand. In our sample, 40 networks terminated their brands due to merger or acquisition. Therefore, we consider two definitions of "exit" in our survival analysis. First, we treat both types of exits equally. In the case of merger or acquisition, we consider a network exiting if the network brand was terminated. Second, we consider networks that "exit" are the ones that exited from the market without merger or acquisition. Under this definition, those networks that were acquired by or merged with another network and terminated their brand are treated as censored observations of exits, acknowledging that they might have survived longer if they had remained independent. ${ }^{22}$

\footnotetext{
${ }^{22}$ If a network simply exits from the market without being acquired by or merged with another network, it is likely that the network has failed and liquidated. However, if a network is acquired by or merged with another one, it may not have failed. Rather, in many cases, a successful network can become a target of merger and acquisition, which means that the network might have survived longer if it had remained independent.
} 


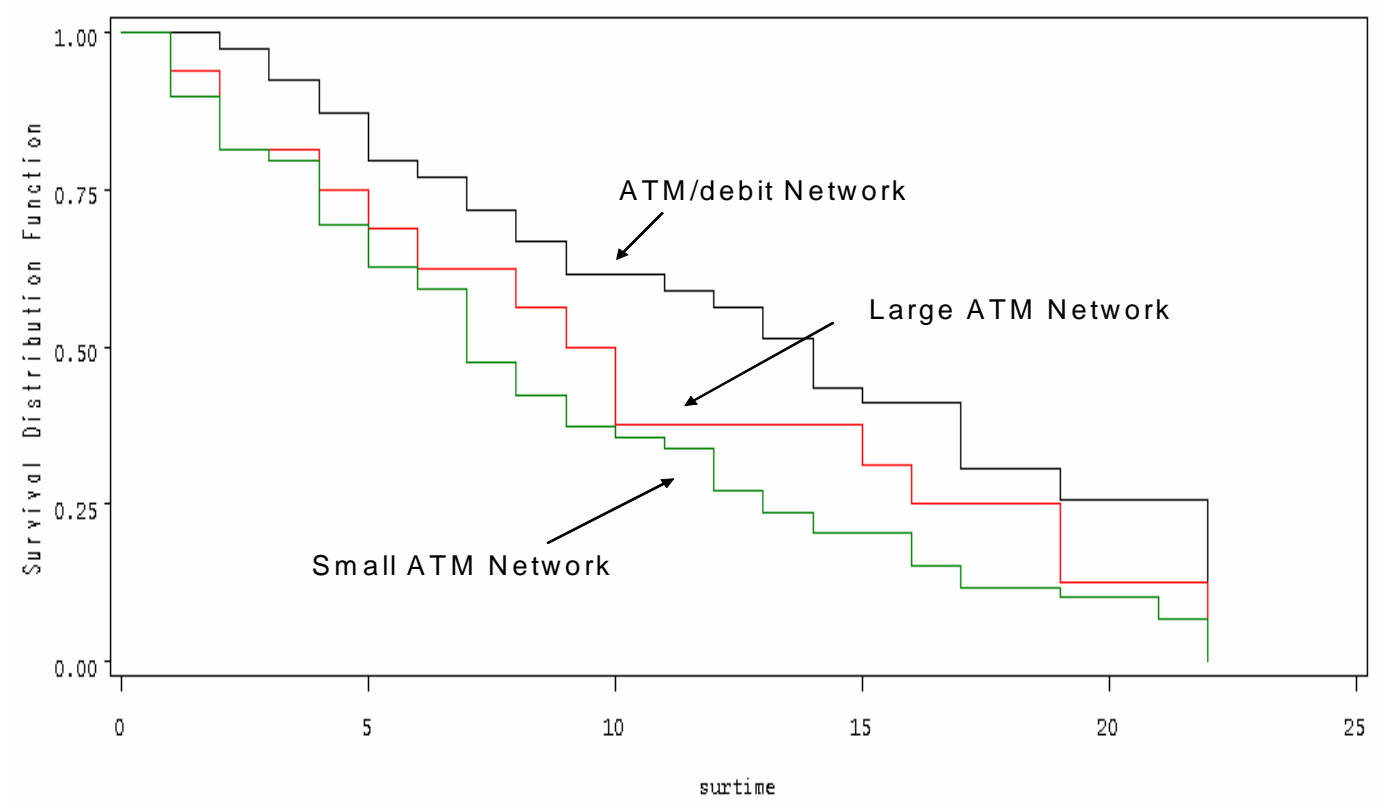

Figure 2: Survival Functions of Networks: M\&A Uncensored

Figures 2 and 3 plot the survival functions for different types of networks during 1985-2006 based on the two definitions of "exit." In either case, the finding supports our theoretical prediction: The ATM/debit networks show the highest survival rates, and large ATM-only networks are more likely to survive than small ATM-only networks. Moreover, as we expect, the results are stronger when we consider merger and acquisition as censored exit.

We analyze network survival using the semi-parametric Cox Proportional Hazards model. In this model, the conditional hazard function, given the covariate vector $X$, is assumed to take the form:

$$
H(t ; X)=H_{0}(t) \exp (X \gamma),
$$

where $\gamma$ is the vector of regression coefficients and $H_{0}(t)$ denotes the baseline hazard function. The baseline hazard $H_{0}(t)$ is left unspecified, allowing for time-varying hazard rates due to common industry shocks.

All covariates in vector $X$ are time-invariant. ${ }^{23}$ Networks that entered in the 1970s

\footnotetext{
${ }^{23}$ We also estimated the model using time-varying covariates in our robustness checks and the results are similar (See Table B in the Appendix).
} 


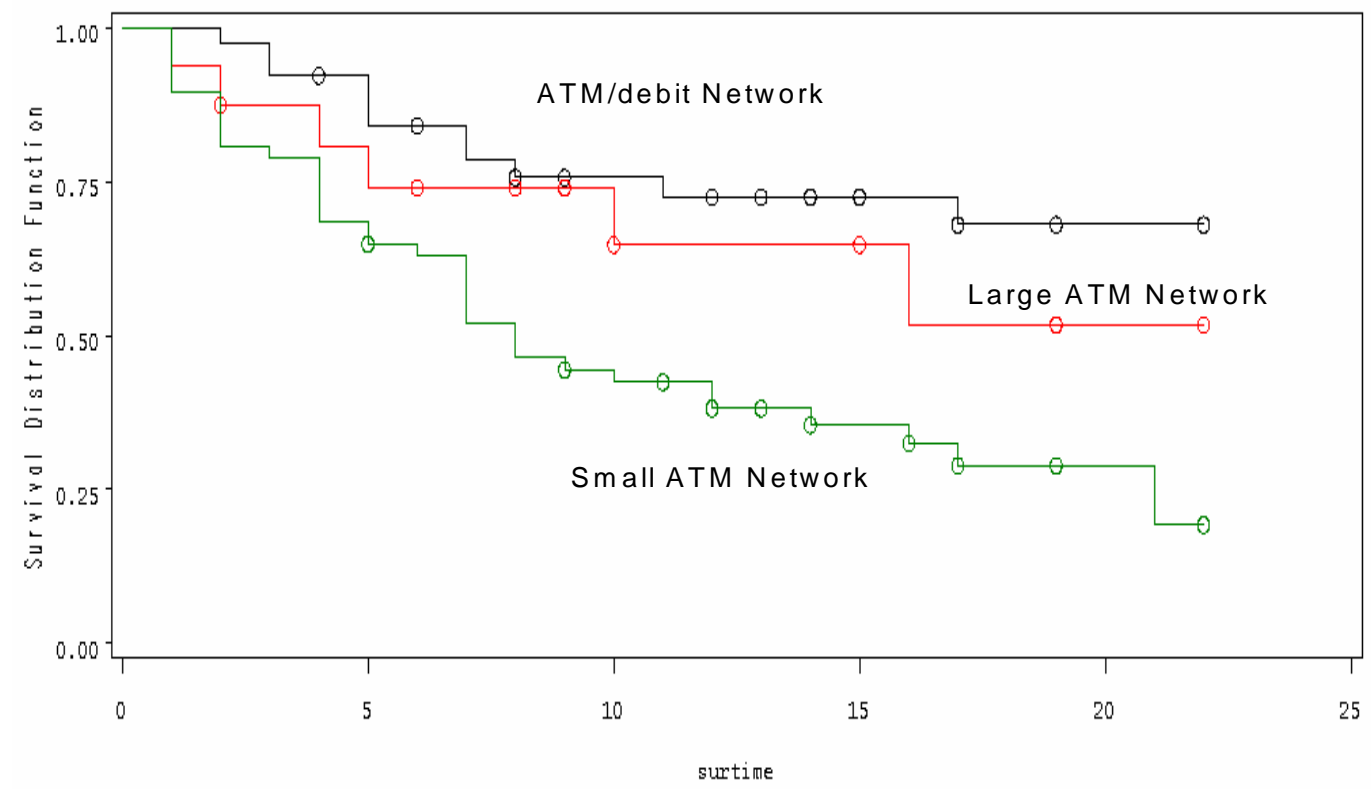

Figure 3: Survival Functions of Networks: M\&A Censored

are categorized as Early cohort. Two ownership dummies (Single owner and Bank owner(s)), two location dummies (East and West), and one size dummy (Large) are based on the networks' 1985 characteristics. The POS dummy indicates whether a network has adopted POS debit by 1987 or not. Finally, the Large ATM dummy indicates whether a network was ranked among the top one-third of networks in 1985 and remained as an ATM-only network by 1987 or not.

Table 3 reports the estimation results. Panel A presents the results treating both types of exits equally and panel B presents the results treating mergers and acquisitions as censored. Specifications 1 and 2 include early cohort, location and ownership dummies. Without controlling for network size and POS adoption, no variable is statistically significant in the uncensored model, and only the Single owner dummy is significant in the censored model. As we will explain later, singly owned networks tend to be small so the Single owner dummy may act as a proxy for network size.

Specification 3 includes the POS dummy along with early cohort, location and ownership dummies. In both uncensored and censored models, the coefficient for the POS 
Table 3. Effects on the Hazard of Exit (1985-2006)

3A. Mergers and Acquisitions Uncensored

\begin{tabular}{lccccc}
\hline \hline & \multicolumn{5}{c}{ Specification } \\
\cline { 2 - 6 } Variable & 1 & 2 & 3 & 4 & 5 \\
\hline Early cohort & -0.149 & -0.197 & -0.120 & -0.090 & -0.069 \\
& $(0.215)$ & $(0.226)$ & $(0.231)$ & $(0.230)$ & $(0.233)$ \\
East & 0.288 & 0.315 & 0.280 & $0.426^{*}$ & 0.381 \\
& $(0.232)$ & $(0.234)$ & $(0.235)$ & $(0.240)$ & $(0.246)$ \\
West & -0.123 & -0.113 & -0.106 & -0.063 & -0.114 \\
& $(0.266)$ & $(0.268)$ & $(0.270)$ & $(0.270)$ & $(0.269)$ \\
Single owner & & 0.154 & 0.122 & -0.007 & 0.031 \\
& & $(0.204)$ & $(0.206)$ & $(0.216)$ & $(0.215)$ \\
Bank owner(s) & & 0.108 & -0.011 & 0.079 & -0.051 \\
& & $(0.256)$ & $(0.260)$ & $(0.257)$ & $(0.262)$ \\
POS & & & $-0.473^{* *}$ & & $-0.582^{* * *}$ \\
& & & $(0.206)$ & & $(0.220)$ \\
Large & & & & $-0.455^{* *}$ & \\
Large ATM & & & & & $-0.222)$ \\
Log likelihood & -445.602 & -445.284 & -442.533 & -443.117 & -441.659 \\
\hline
\end{tabular}

Notes: Standard errors are in parentheses. Ownership, location, and size are based on networks' 1985 characteristics. POS=1, if a network adopted POS debit by 1987, otherwise an ATM-only network. ***,**, *: Significant at the $.01, .05$, and .10 level, respectively.

\section{B. Mergers and Acquisitions Censored}

\begin{tabular}{lccccc}
\hline \hline \multirow{2}{*}{ Variable } & \multicolumn{5}{c}{ Specification } \\
\cline { 2 - 6 } Early cohort & 0.265 & 0.196 & 0.311 & 0.387 & 0.405 \\
& $(0.284)$ & $(0.305)$ & $(0.313)$ & $(0.303)$ & $(0.315)$ \\
East & 0.391 & 0.463 & 0.381 & $0.696^{* *}$ & $0.538^{*}$ \\
& $(0.312)$ & $(0.312)$ & $(0.311)$ & $(0.316)$ & $(0.321)$ \\
West & -0.176 & -0.175 & -0.131 & -0.013 & -0.127 \\
& $(0.393)$ & $(0.393)$ & $(0.397)$ & $(0.397)$ & $(0.398)$ \\
Single owner & & $0.607^{* *}$ & $0.589^{*}$ & 0.244 & 0.400 \\
& & $(0.313)$ & $(0.319)$ & $(0.321)$ & $(0.328)$ \\
Bank owner(s) & & -0.229 & -0.427 & -0.255 & -0.493 \\
& & $(0.336)$ & $(0.341)$ & $(0.333)$ & $(0.343)$ \\
POS & & & $-1.137^{* * *}$ & & $-1.279^{* * *}$ \\
& & & $(0.206)$ & & $(0.220)$ \\
Large & & & & $-1.291^{* * *}$ & \\
Large ATM & & & & $(0.384)$ & \\
& & & & & $-0.802^{*}$ \\
Log likelihood & -248.472 & -245.942 & -239.223 & -238.903 & -237.58 \\
\hline
\end{tabular}

Notes: Standard errors are in parentheses. Ownership, location, and size are based on networks' 1985 characteristics. POS=1, if a network adopted POS debit by 1987, otherwise an ATM-only network. ***,**, *: Significant at the .01, .05, and .10 level, respectively. 
dummy is negative and statistically significant, which implies networks that have adopted the POS debit innovation are more likely to survive than networks that have not. While the coefficient for the POS dummy in the uncensored model is statistically significant at the 5 percent level, the same coefficient in the censored model is statistically significant at the 1 percent level. In addition, the magnitude of the coefficient is much larger in the censored model. These results suggest that networks which have adopted POS debit are less likely to exit from the market, and if they do, they are more likely to be acquired or merged with another network. In contrast, networks that have not adopted POS debit are more likely to exit, especially through failure and liquidation.

Specification 4 includes the Large dummy, instead of POS dummy, along with early cohort, location and ownership dummies. Similar to the POS dummy, the coefficient for the Large dummy is negative and statistically significant in both uncensored and censored models. The results suggest that large networks are less likely to exit from the market, and if they do, they are more likely to be acquired or merged.

Finally, specification 5 includes the POS and Large ATM dummies, which are mutually exclusive, along with early cohort, ownership, and location dummies. The coefficient for the POS dummy is negative and statistically significant in both uncensored and censored models. Meanwhile, the coefficient for Large ATM is negative and statistically significant in the censored model, which suggests that compared with large ATM-only networks, small ATM-only networks are more likely to exit through failure and liquidation. Note that the coefficient for the POS dummy is much greater than that for the Large ATM dummy in the censored model (1.28 vs. 0.80). In terms of hazard ratio, this means an ATM/debit network's risk of exit relative to a small ATM-only network is 32 percent, but a large ATM-only network's risk of exit relative to a small ATM-only network is 45 percent. These findings support our hypothesis: ATM/debit networks are more likely to survive than ATM-only networks, and large ATM-only networks are more likely to survive than small ATM-only networks.

In specifications 3-5, after controlling for the network size and/or POS adoption, most variables except the East dummy are not statistically significant. Networks located in 
the East tend to have a higher exit rate than networks located in the other regions, and the effect becomes more significant in the censored model. The coefficient for Early cohort, being negative in the uncensored model but positive in the censored model, is never statistically significant. The coefficient for Single owner shows a positive sign and is statistically significant in the specification 3 of the censored model, where the POS adoption but not the network size is controlled. Again, this can be explained by that Single owner dummy may act as a proxy for the size of ATM-only networks. Meanwhile, the coefficient for Bank owner(s) shows a negative sign in all specifications of the censored model, but is never statistically significant. Among these findings, the effects of Early cohort and Single owner are particularly interesting and in contrast to previous studies in the literature. We will further examine them in Subsection 4.4.

\subsubsection{Robustness Checks}

In addition to the above base regressions, we perform a series of robustness checks. First, we re-estimate the hazard model on a sub-sample consisting of years 1985-1995. Recall that more industry changes took places after the mid 1990s, such as interstate banking deregulation and increasing nonbank ownership. While our base regressions leave the baseline hazard function unspecified to allow for time-varying hazard rates, using the pre-1995 sub-sample provides an alternative way to isolate the later industry shocks. The results, as shown in Table A in the Appendix, are very similar to our base regression results.

Second, we re-estimate the hazard model using time-varying covariates so that a network's characteristics at the time of exit together with the information on its survival up to that period are used in explaining the network's hazard rate. The results, reported in the Appendix Table B, again are very similar.

Third, we check for potential endogeneity issues. One concern is that if the POS debit adopters were mainly large networks, they might have other advantages, besides adopting the debit innovation, that determined their higher survival rates than small networks. One way to address this concern is to re-estimate the hazard model within 
the subgroup of large or small networks. The results, reported in the Appendix Table C, confirm our base findings: Even within the subgroup of large or small networks, adopting the debit innovation significantly reduces the hazard of network exit.

Fourth, re-estimating the hazard model based on propensity scores is another way to address some of the endogeneity concerns, such as the potential reverse causality between debit adoption and network survival. Using the result of our debit adoption

regression (Table 2, specification 3), we first calculate the propensity score of debit adoption for each network. We then re-estimate the hazard model within the subgroup of networks whose propensity scores are ranked among the top or bottom quarter. In the top or bottom subgroup, the networks are similar in size, either all large or all small. After controlling for the propensity score, the adoption of POS debit is presumably purely random. The results, reported in the Appendix Table D, again confirm our base findings: Even within the subgroup of networks with similar propensity scores, adopting the debit innovation significantly reduces the hazard of network exit.

Finally, we consider alternative measures of network size. In our base regressions, an ATM network's size is measured by its number of cards in circulation. Alternatively, we use the number of ATM transactions or the number of ATM terminals to measure network size. Again, the results are very similar.

\subsection{First-Mover (Dis)Advantages}

The finding that early entrants in the ATM and debit card industry do not show significant advantages in product innovation and network survival is in sharp contrast to previous studies in the literature. Those studies, focusing on shakeouts in manufacturing industries, typically found that early entrants enjoy substantial first-mover advantages. As explained in Klepper (1996), early entrants have time to build a large production scale, which makes it easier for them to adopt technological innovations because the resulting decrease in average cost can be applied over a larger level of output than for other firms. As price-cost margins decline over time, late entrant are the first to succumb to competitive exit and the early entrants eventually take over an increasing share of the 
industry's output. Therefore, early entrants are more likely to adopt innovations and survive the shakeout.

However, this mechanism does not appear to play an important role in the ATM and debit card industry. Table 4 presents a correlation analysis between variables on network size, entry cohort, ownership and location, based on the information in 1985 . The results show no statistically significant correlation between Early cohort and Large network. Rather, both Early cohort and Large network are significantly correlated with network ownership structures - Single owner and/or Bank owner(s).

To further explore the issue, we conduct logit regressions using either Early cohort or Large network as the dependent variable. The results are reported in Table 5. The coefficients for Single owner and Bank owner(s) are found positive and statistically significant in the Early cohort regression, indicating the bias of early entrants' ownership structure. In the Large network regression, without controlling for ownership, the coefficient of Early cohort shows a positive sign but is not statistically significant. After controlling for ownership, the effect of Early cohort becomes stronger though still not statistically significant. ${ }^{24}$ Meanwhile, the coefficients for Single owner and Bank owner(s) are both negative in the Large network regression, and the Single owner is statistically significant. These findings suggest that early entrants in the ATM and debit card industry did not enjoy strong first-mover advantages, but rather suffered some disadvantages in organizational structure.

In fact, our theoretical model can shed some light on these findings. According to our theory, a potential entrant may either pay a low cost to enter as a small network or pay a high cost to enter as a large network. If we interpret the time and efforts on coordinating among network partners as a part of the entry cost, then early entrants are more likely to be singly owned small networks and late entrants are more likely to be jointly owned large networks. Therefore, even if there were some first-mover advantages, they would be partially offset by the early entrants' disadvantages in organizational structure.

\footnotetext{
${ }^{24}$ Based on the coefficient estimates of the logit regressions, we can construct the marginal effects of Early cohort on Large network. The results show that the effect is stronger if the ownership is controlled.
} 
Table 4. Correlation: Size, Cohort, Ownership, and Location

\begin{tabular}{|c|c|c|c|c|c|c|}
\hline Variable & Large & $\begin{array}{l}\begin{array}{l}\text { Early } \\
\text { cohort }\end{array} \\
\end{array}$ & $\begin{array}{l}\text { Single } \\
\text { owner }\end{array}$ & $\begin{array}{c}\text { Bank } \\
\text { owner(s) }\end{array}$ & East & 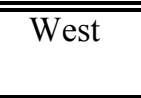 \\
\hline Large & 1 & $\begin{array}{c}0.014 \\
(0.884)\end{array}$ & $\begin{array}{l}-0.256^{* * *} \\
(0.006)\end{array}$ & $\begin{array}{c}0.016 \\
(0.868)\end{array}$ & $\begin{array}{l}0.245^{* * *} \\
(0.009)\end{array}$ & $\begin{array}{c}0.051 \\
(0.590)\end{array}$ \\
\hline Early cohort & & 1 & $\begin{array}{c}0.204^{* *} \\
(0.029)\end{array}$ & $\begin{array}{c}0.207^{* *} \\
(0.028)\end{array}$ & $\begin{array}{l}-0.175^{*} \\
(0.063)\end{array}$ & $\begin{array}{l}-0.003 \\
(0.976)\end{array}$ \\
\hline Single owner & & & 1 & $\begin{array}{l}-0.060 \\
(0.529)\end{array}$ & $\begin{array}{l}-0.145 \\
(0.125)\end{array}$ & $\begin{array}{c}0.089 \\
(0.347)\end{array}$ \\
\hline Bank owner(s) & & & & 1 & $\begin{array}{l}-0.031 \\
(0.745)\end{array}$ & $\begin{array}{l}-0.093 \\
(0.325)\end{array}$ \\
\hline East & & & & & 1 & $\begin{array}{l}-0.247^{* * *} \\
(0.008)\end{array}$ \\
\hline West & & & & & & 1 \\
\hline
\end{tabular}

Notes: P-values are in parentheses. Ownership, location, and size are based on the networks' 1985 characteristics. $* * *, * *, *$ : Significant at the $.01, .05$, and .10 level, respectively.

Table 5. Logit Models: Early Cohort and Large Network

\begin{tabular}{lccc}
\hline \hline \multirow{2}{*}{ Variable } & \multirow{2}{*}{ Early cohort } & \multicolumn{2}{c}{ Large } \\
\cline { 2 - 4 } Constant & $-2.941^{* * *}$ & $-1.298^{* * *}$ & -0.702 \\
& $(0.892)$ & $(0.334)$ & $(0.612)$ \\
Early cohort & & 0.332 & 0.629 \\
& & $(0.468)$ & $(0.506)$ \\
Single owner & $1.092^{* *}$ & & $-1.208^{* * *}$ \\
& $(0.500)$ & & $(0.452)$ \\
Bank owner(s) & $1.731^{* *}$ & & -0.003 \\
& $(0.796)$ & & $(0.570)$ \\
East & $-1.040^{*}$ & $1.394^{* * *}$ & $1.369^{* * *}$ \\
& $(0.620)$ & $(0.489)$ & $(0.506)$ \\
West & -0.176 & 0.751 & 0.923 \\
& $(0.618)$ & $(0.565)$ & $(0.594)$ \\
Log likelihood & -60.272 & -68.215 & -64.476 \\
\hline
\end{tabular}

Notes: Standard errors are in parentheses. Ownership, location, and size are based on the networks' 1985 characteristics. ***, **, *: Significant at the $.01, .05$, and .10 level, respectively. 
The finding that early entrants may suffer disadvantages in organizational structures is not unique to the ATM and debit card industry, but also is supported by evidence from other network industries. For example, the U.S. credit card industry started in the 1950s and the earliest entrants were mainly singly owned, proprietary systems, such as Diners Club, American Express as well as many other small ones. It was not until the mid 1960s, the co-opetitive model emerged when banks formed associations to market their cards jointly. These card associations were owned and operated by member banks, which competed for merchants and cardholders but cooperated at the card system level by setting operational standard. Eventually, the credit card industry was dominated by two largest co-opetitive networks, Visa and MasterCard, which account for more than 80 percent of U.S. credit card market share today (Evans and Schmalensee, 2005). A similar but more recent example is the U.S. smartphone operating system industry, where a later entrant, the open-source Android system, is surpassing the first movers - the closed source, proprietary systems of iPhone and Blackberry - in terms of new handsets sold and total subscribers. ${ }^{25}$

\section{Conclusion}

The U.S. ATM and debit card industry is an intriguing example of the broader debate on industrial evolution. Unlike most manufacturing industries studied in the literature, the ATM and debit card industry is a financial service industry featuring strong network effects. The industry started with a few shared ATM networks in the early 1970s.

\footnotetext{
${ }^{25}$ The major players in the U.S. Smartphone operating system industry are the Blackberry, iPhone and Android, which were introduced in 2002, 2007 and 2008 respectively. Both Blackberry and iPhone operating systems are closed source, proprietary systems, which restrict the use of third party software and require exclusive devices (Blackberry or iPhone). The iPhone also exclusively operates on the AT\&T network. In contrast, the Android was an effort by a consortium of hardware, software, and telecom companies devoted to advancing open standards for mobile devices. Multiple devices can run on the Android platform, and the phones can operate on any network in the Open Handset Alliance (which includes T-Mobile, AT\&T, Verizon, Sprint). According to the NPD Group, a leading market research company, Android's operating system was installed in 44 percent of all smartphones purchased in the third quarter 2010, comparing with 23 percent for the iPhones and 22 percent for the Blackberries. In terms of total subscribers, Android is expected to surpass iPhone and Blackberry in the first quarter of 2011 if the current trends hold up.
} 
The number of shared networks grew rapidly until the mid 1980s, but declined sharply afterwards. This raises interesting research questions: What drove the industry shakeout in spite of the rising ATM transaction volume? Which ATM networks had fared better than others through the consolidation?

This paper sheds light on these questions by focusing on the role that a major network-enhancing product innovation - introducing the debit function in the mid 1980s - played in driving the network consolidation. We construct a theoretic model to characterize the impact of the debit innovation. The debit function allows customers to use ATM/debit cards to pay for goods and services at retail places, which extends the industry from a one-sided market of ATM services into a two-sided market serving both consumers and merchants at the point of sale. As a result, the enhanced network effects spurred a debit adoption race among the ATM networks, in which large networks had better advantages due to their cardholder base and infrastructures in place. Eventually, the winners of the race survived and expanded, and the losers had to exit.

While introducing the POS debit function was not the only force shaping the industry evolution, by focusing on this major event, we are able to sort out the complex relations among product innovation, industry shakeout and network survival. The theoretical hypotheses are tested using a novel dataset on network entry, exit, size, location, ownership and product choices. Consistent with the theory, we find that large ATM networks had a better chance of adopting the debit innovation and surviving the shakeout. Moreover, in contrast to previous studies, we find little advantage of being an early entrant in this network industry. Rather, ownership and organizational structure had an important influence on network size and survival. 
Table A. Effects on the Hazard of Exit (1985-1995) Mergers and Acquisitions Censored

\begin{tabular}{lccccc}
\hline \hline \multirow{2}{*}{ Variable } & \multicolumn{5}{c}{ Specification } \\
\cline { 2 - 6 } Early cohort & 1 & 2 & 3 & 4 & 5 \\
& 0.287 & 0.198 & 0.319 & 0.380 & 0.410 \\
East & $(0.284)$ & $(0.303)$ & $(0.313)$ & $(0.302)$ & $(0.316)$ \\
& 0.376 & 0.453 & 0.374 & $0.694^{* *}$ & 0.519 \\
West & $(0.311)$ & $(0.311)$ & $(0.310)$ & $(0.315)$ & $(0.320)$ \\
& -0.164 & -0.186 & -0.126 & -0.014 & -0.115 \\
Single owner & $(0.393)$ & $(0.393)$ & $(0.397)$ & $(0.398)$ & $(0.398)$ \\
& & $0.626^{* *}$ & $0.618^{*}$ & 0.295 & 0.450 \\
Bank owner(s) & & $(0.315)$ & $(0.321)$ & $(0.323)$ & $(0.330)$ \\
& & -0.256 & -0.440 & -0.286 & -0.504 \\
POS & & $(0.333)$ & $(0.338)$ & $(0.329)$ & $(0.341)$ \\
& & & $-1.118^{* * *}$ & & $-1.243^{* * *}$ \\
Large & & & $(0.341)$ & & $(0.347)$ \\
& & & & $-1.233^{* *}$ & \\
Large ATM & & & & $(0.382)$ & \\
& & & & & -0.738 \\
Log likelihood & -252.901 & -250.174 & -243.671 & -243.751 & -242.277 \\
\hline
\end{tabular}

Notes: Standard errors are in parentheses. Ownership, location, and size are based on the networks' 1985 characteristics. POS=1, if a network adopted POS debit by 1987 , otherwise an ATM-only network. ***, **, *: Significant at the $.01, .05$, and .10 level, respectively.

Table B. Effects on the Hazard of Exit (1985-2006)

Time-varying Covariates Mergers and Acquisitions Censored

\begin{tabular}{|c|c|c|c|c|c|}
\hline \multirow[b]{2}{*}{ Variable } & \multicolumn{5}{|c|}{ Specification } \\
\hline & 1 & 2 & 3 & 4 & 5 \\
\hline \multirow{2}{*}{ Early cohort } & 0.184 & 0.105 & 0.223 & 0.237 & 0.295 \\
\hline & $(0.249)$ & $(0.254)$ & $(0.257)$ & $(0.257)$ & $(0.258)$ \\
\hline \multirow[t]{2}{*}{ East } & 0.260 & 0.257 & $0.491^{*}$ & 0.466 & $0.576^{*}$ \\
\hline & $(0.280)$ & $(0.280)$ & $(0.292)$ & $(0.288)$ & $(0.297)$ \\
\hline \multirow[t]{2}{*}{ West } & 0.040 & 0.048 & 0.238 & 0.099 & 0.225 \\
\hline & $(0.339)$ & $(0.341)$ & $(0.350)$ & $(0.342)$ & $(0.350)$ \\
\hline \multirow[t]{2}{*}{ Single owner } & & $0.732^{* *}$ & 0.465 & 0.504 & 0.372 \\
\hline & & $(0.315)$ & $(0.325)$ & $(0.316)$ & $(0.327)$ \\
\hline \multirow[t]{2}{*}{ Bank owner(s) } & & 0.168 & -0.034 & 0.091 & -0.012 \\
\hline & & $(0.298)$ & $(0.301)$ & $(0.300)$ & $(0.300)$ \\
\hline \multirow[t]{2}{*}{ POS } & & & $-0.898^{* * *}$ & & $-1.027^{* * *}$ \\
\hline & & & $(0.306)$ & & $(0.312)$ \\
\hline \multirow[t]{2}{*}{ Large } & & & & $-1.143^{* * *}$ & \\
\hline & & & & $(0.337)$ & \\
\hline \multirow[t]{2}{*}{ Large ATM } & & & & & $-0.836^{*}$ \\
\hline & & & & & $(0.483)$ \\
\hline Log likelihood & -293.502 & -290.435 & -285.622 & -283.317 & -283.797 \\
\hline
\end{tabular}

Notes: Standard errors are in parentheses. Ownership, location, and size are based on the networks' 1985 characteristics. POS=1, if a network adopted POS debit by 1987, otherwise an ATM-only network. ***,**,*: Significant at the .01, .05, and .10 level, respectively. 
Table C. Effects on the Hazard of Exit (1985-2006)

Separate Estimation for Large and Small Networks

Mergers and Acquisition Censored

\begin{tabular}{lcccc}
\hline \hline \multirow{2}{*}{ Variable } & \multicolumn{2}{c}{ Large } & \multicolumn{2}{c}{ Small } \\
\cline { 2 - 5 } Early cohort & Spec.1 & Spec. & Spec.1 & Spec.2 \\
& 0.395 & -0.606 & 0.426 & 0.486 \\
East & $(0.909)$ & $(1.034)$ & $(0.323)$ & $(0.332)$ \\
& $1.512^{*}$ & 1.072 & $0.600^{*}$ & 0.525 \\
West & $(0.830)$ & $(0.808)$ & $(0.360)$ & $(0.360)$ \\
& -0.048 & 0.326 & 0.071 & 0.007 \\
Single owner & $(1.168)$ & $(1.199)$ & $(0.425)$ & $(0.429)$ \\
& 1.287 & $2.246^{* *}$ & 0.072 & 0.094 \\
Bank owner(s) & $(0.804)$ & $(1.057)$ & $(0.345)$ & $(0.348)$ \\
& -1.184 & -0.855 & -0.142 & -0.336 \\
POS & $(0.882)$ & $(0.839)$ & $(0.372)$ & $(0.385)$ \\
& & $-1.814^{* *}$ & & $-0.705^{*}$ \\
Log likelihood & -26.489 & -24.447 & -185.944 & -184.212 \\
Number of networks & 38 & 38 & 76 & 76 \\
\hline
\end{tabular}

Notes: Standard errors are in parentheses. Ownership, location, and size are based on the networks' 1985 characteristics. POS $=1$, if a network adopted POS debit by 1987, otherwise an ATM-only network. ***,**, : Significant at the $.01, .05$, and .10 level, respectively.

Table D. Effects on the Hazard of Exit (1985-2006)

Separate Estimation for Top and Bottom Quarters in Propensity Score Mergers and Acquisition Censored

\begin{tabular}{|c|c|c|c|c|}
\hline \multirow[b]{2}{*}{ Variable } & \multicolumn{2}{|c|}{ Top } & \multicolumn{2}{|c|}{ Bottom } \\
\hline & Spec. 1 & Spec. 2 & Spec. 1 & Spec. 2 \\
\hline Early cohort & $\begin{array}{c}0.460 \\
(0.995)\end{array}$ & $\begin{array}{c}-0.778 \\
(1.156)\end{array}$ & $\begin{array}{c}0.699 \\
(0.515)\end{array}$ & $\begin{array}{c}1.007^{*} \\
(0.520)\end{array}$ \\
\hline East & $\begin{array}{c}2.085^{*} \\
(1.198)\end{array}$ & $\begin{array}{c}1.518 \\
(1.041)\end{array}$ & $\begin{array}{c}0.870 \\
(0.638)\end{array}$ & $\begin{array}{c}0.251 \\
(0.677)\end{array}$ \\
\hline West & $\begin{array}{c}0.517 \\
(1.264)\end{array}$ & $\begin{array}{c}0.984 \\
(1.378)\end{array}$ & $\begin{array}{l}-0.519 \\
(0.715)\end{array}$ & $\begin{array}{l}-0.269 \\
(0.841)\end{array}$ \\
\hline Single owner & $\begin{array}{l}-0.119 \\
(1.302)\end{array}$ & $\begin{array}{c}1.053 \\
(1.378)\end{array}$ & $\begin{array}{l}-0.298 \\
(0.557)\end{array}$ & $\begin{array}{c}0.213 \\
(0.619)\end{array}$ \\
\hline Bank owner(s) & $\begin{array}{l}-1.577^{*} \\
(1.326)\end{array}$ & $\begin{array}{l}-0.897 \\
(1.183)\end{array}$ & $\begin{array}{l}-0.847^{*} \\
(0.481)\end{array}$ & $\begin{array}{l}-1.532^{* * *} \\
(0.533)\end{array}$ \\
\hline POS & & $\begin{array}{l}-1.951^{*} \\
(1.030)\end{array}$ & & $\begin{array}{l}-2.015^{* *} \\
(0.862)\end{array}$ \\
\hline Log likelihood & -17.524 & -15.697 & -76.499 & -72.578 \\
\hline Number of networks & 25 & 25 & 40 & 40 \\
\hline
\end{tabular}

Notes: Standard errors are in parentheses. Ownership, location, and size are based on the networks' 1985 characteristics. POS $=1$, if a network adopted POS debit by 1987, otherwise an ATM-only network. ***,**, *: Significant at the $.01, .05$, and .10 level, respectively. 


\section{References}

[1] Chandler, Alfred D., Jr., (1990). Scale and Scope: The Dynamics of Industrial Capitalism. Cambridge, MA and London: Harvard University Press.

[2] Evans, David and Richard Schmalensee (2005), Paying with Plastic: The Digital Revolution in Buying and Borrowing, 2nd Ed., MIT Press, Cambridge, MA.

[3] Felgran, Steven D, (1985). "From ATM to POS Networks: Branching, Access, and Pricing," New England Economic Review, (May-June), 44-61.

[4] Felgran, Steven D, (1984). "Shared ATM Networks: Market Structure and Public Policy," New England Economic Review, (February) 23-38.

[5] Gort, Michael and Steven Klepper, (1982). "Time Paths in the Diffusion of Product Innovations," The Economic Journal, 92, (Sept.), 630-653.

[6] Gowrisankaran, Gautam and John Krainer, (2006). "The Welfare Consequences of ATM Surcharges: Evidence from a Structural Entry Model," NBER Working Papers 12443.

[7] Hannan, Timothy H., (2007). "ATM Surcharge Bans and Bank Market Structure: The Case of Iowa and Its Neighbors," Journal of Banking and Finance, 31(4), 1061-1082.

[8] Hannan, Timothy H. and Ron Borzekowski, (2007). "Incompatibility and Investment in ATM Networks," Review of Network Economics, 6(1), 1-15.

[9] Hannan, Timothy H and John M McDowell, (1984). "Market Concentration and the Diffusion of New Technology in the Banking Industry," Review of Economics and Statistics, 66(4), 686-91.

[10] Hayashi, Fumiko, Richard Sullivan, and Stuart E. Weiner, (2003). A Guide to the ATM and Debit Card Industry. Federal Reserve Bank of Kansas City.

[11] Hayashi, Fumiko, Richard Sullivan, and Stuart E. Weiner, (2006). A Guide to the ATM and Debit Card Industry: 2006 Update. Federal Reserve Bank of Kansas City. 
[12] Hermalin, Benjamin and Michael Katz, (2006). "Your Network or Mine? The Economics of Routing Rules," Rand Journal of Economics, 37 (3).

[13] Humphrey, David B., Moshe Kim and Bent Vale, (2001). "Realizing the Gains from Electronic Payments: Costs, Pricing, and Payment Choice," Journal of Money, Credit and Banking, 33, 216-234.

[14] Ishii, Joy, (2005). "Interconnection Pricing, Compatibility, and Investment in Network Industries: ATM Networks in the Banking Industry," working paper.

[15] Jovanovic, Boyan and Glenn M. MacDonald, (1994). "The Life Cycle of a Competitive Industry," Journal of Political Economy, 102 (Apr.), 322-347.

[16] Klepper, Steven, (1996). "Entry, Exit, Growth, and Innovation over the Product Life Cycle," American Economic Review, 86 (June), 562-583.

[17] Klepper, Steven and Elizabeth Graddy, (1990). "The Evolution of New Industries and the Determinants of Market Structure," Rand Journal of Economics, 21, $27-44$.

[18] Klepper, Steven and Kenneth Simons, (2005). "Industry Shakeouts and Technological Change," International Journal of Industrial Organization, 23, 23-43.

[19] Klepper, Steven and Kenneth Simons, (2000). "The Making of an Oligopoly: Firm Survival and Technological Change in the Evolution of the U.S. Tire Industry," Journal of Political Economy, 108, 4, 728-758.

[20] Knittel, Chris and Victor Stango, (2008). "Incompatibility, Product Attributes and Consumer Welfare: Evidence from ATMs," The B.E. Journal of Economic Analysis and Policy (Advances), 8(1).

[21] Knittel, Chris and Victor Stango, (2008). "How Does Incompatibility Affect Prices? Evidence from ATMs," Journal of Industrial Economics, in press.

[22] Lieberman, Marvin and David Montgomery (1998). "First-Mover (Dis)Advantages: Retrospective and Link with Resource-Based View," Strategic Management Journal, 19(12), 1111-1125. 
[23] Lieberman, Marvin and David Montgomery (1988). "First-Mover Advantages," Strategic Management Journal, 9, 41-58.

[24] Massoud, Nadia and Dan Bernhardt, (2002). "Rip-off ATM Surcharges," Rand Journal of Economics, 33 (1).

[25] Matutes, Carmen and Atilano Jorge Padilla, (1994). "Shared ATM Networks and Banking Competition," European Economic Review, 38, 1113-38.

[26] McAndrews, James J., (2003). "Automated Teller Machine Network Pricing - A Review of the Literature," Review of Network Economics, 2(2), 146-158.

[27] Rochet, Jean-Charles and Jean Tirole, (2003). "Platform Competition in Two-Sided Markets," Journal of the European Economic Association, 1(4): 990-1029.

[28] Saloner, Garth and Andrea Shephard, (1995). "Adoption of Technologies with Network Effects: An Empirical Examination of the Adoption of Automated Teller Machines," RAND Journal of Economics, 26, 479-501.

[29] Wang, Zhu, (2008). "Income Distribution, Market Size and the Evolution of Industry," Review of Economic Dynamics, 11 (3), 542-565.

[30] Wang, Zhu, (2007). "Technological Innovation and Market Turbulence: The Dotcom Experience," Review of Economic Dynamics, 10 (1), 78-105. 